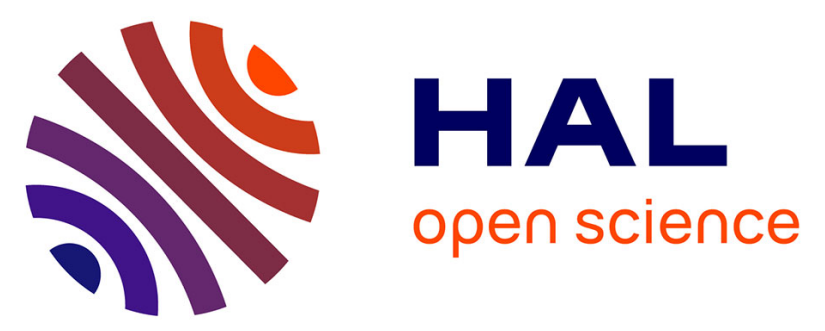

\title{
Using hydrogen isotope incorporation as a tool to unravel the surfaces of hydrogen-treated nanodiamonds
}

Emilie Nehlig, Sébastien Garcia-Argote, Sophie Feuillastre, Mélanie Moskura,

Thibault Charpentier, Michel Schleguel, Hugues Girard, Jean-Charles

Arnault, Grégory Pieters

\section{To cite this version:}

Emilie Nehlig, Sébastien Garcia-Argote, Sophie Feuillastre, Mélanie Moskura, Thibault Charpentier, et al.. Using hydrogen isotope incorporation as a tool to unravel the surfaces of hydrogen-treated nanodiamonds. Nanoscale, 2019, 11 (16), pp.8027-8036. 10.1039/C9NR01555H . cea-02184407

\section{HAL Id: cea-02184407 https://hal-cea.archives-ouvertes.fr/cea-02184407}

Submitted on 19 Jul 2019

HAL is a multi-disciplinary open access archive for the deposit and dissemination of scientific research documents, whether they are published or not. The documents may come from teaching and research institutions in France or abroad, or from public or private research centers.
L'archive ouverte pluridisciplinaire HAL, est destinée au dépôt et à la diffusion de documents scientifiques de niveau recherche, publiés ou non, émanant des établissements d'enseignement et de recherche français ou étrangers, des laboratoires publics ou privés. 


\title{
Using hydrogen isotopes incorporation as a tool to unravel surfaces of hydrogen-treated nanodiamonds
}

\author{
Nehlig E. ${ }^{1}$, Garcia-Argote S. ${ }^{1}$, Feuillastre S. ${ }^{1}$, Moskura M. ${ }^{2}$, Charpentier T. ${ }^{2}$, Schleguel M. L. ${ }^{3}$, \\ Girard H.A. ${ }^{4}$, Arnault J.C. ${ }^{4}$, Pieters G. ${ }^{1}$ \\ ${ }^{I}$ CEA, SCBM, Tritium Labelling Laboratory, F-91191 Gif sur Yvette, France \\ ${ }^{2}$ NIMBE, CEA, CNRS, Université Paris-Saclay, CEA Saclay, F-91191 Gif sur Yvette, France \\ ${ }^{3}$ CEA, DEN ; SEARS, Université Paris-Saclay, F-91191 Gif sur Yvette, France \\ ${ }^{4}$ CEA, LIST, Diamond Sensors Laboratory, F-91191 Gif sur Yvette, France
}

\begin{abstract}
We report here on a robust and easy-to-implement method for the labeling of detonation nanodiamonds (DND) with hydrogen isotopes (deuterium and tritium), using thermal annealing performed in a closed system. With this method, we have synthesized and fully characterized (FTIR, Raman, DLS, ${ }^{3} \mathrm{H} /{ }^{2} \mathrm{H} /{ }^{1} \mathrm{H}$ and ${ }^{13} \mathrm{C}$ MAS NMR) deuterium-treated and tritium-treated DND and demonstrated usefulness of the isotope incorporation to investigate the surface chemistry of such nanomaterials. For instance, surface treatment with deuterium coupled to FTIR spectroscopy allowed us to discriminate the origin of the $\mathrm{C}-\mathrm{H}$ terminations at the DND surface after hydrogenation process. Complementary, tritium appeared very useful for quantification purposes, while ${ }^{1,2,3} \mathrm{H}$ NMR confirmed the nature of the $\mathrm{C}_{-}{ }^{1,2,3} \mathrm{H}$ bonds created. This isotopic study provides new insights on the characteristics of hydrogen-treated DND.
\end{abstract}

\section{1) Introduction}

Diamond nanoparticles (or nanodiamonds) are nowadays extensively studied to synthesize composite materials in polymer matrix ${ }^{1}$, to elaborate a new generation of lubricants ${ }^{2}$ and advanced catalysts ${ }^{3}$, to be used as biomarkers and drug delivery nanocarriers in biomedical applications ${ }^{4}$. Among the different sources of nanodiamonds, detonation nanodiamonds (DND) are particularly attractive with a primary particle size of $4-5 \mathrm{~nm}$, a stable inert core and a versatile surface chemistry ${ }^{5}$. Moreover, DND still possess several outstanding properties of bulk diamond like hardness, low friction coefficient, chemical resilience and biocompatibility ${ }^{4}$. Due to the broad scope of their application fields, a deeper understanding and a control of the surface properties of DND is crucial. Different strategies were reported to obtain DND with a homogeneous surface chemistry and stable colloidal stability ${ }^{5}$. In this context, surface hydrogenation appears as a solution of choice $^{6-10}$ because it combines the removal of nondiamond carbons, the reduction of oxygen functional groups and the formation of $\mathrm{C}-\mathrm{H}$ bonds at DND surface.

According to the literature, this surface treatment also confers: 1) a stability in aqueous solutions with a positive Zeta potential ${ }^{11}$ which permits, via an electrostatic grafting, to use DND as a vector of biologics such as small interfering $\mathrm{RNA}^{12}$ or as seeds for diamond growth by chemical vapor deposition ${ }^{13}$; 2) modifications in the structure of water molecules surrounding hydrogen-treated DND compared to other surface chemistries according to 
spectroscopic investigations ${ }^{14,15}$; 3) a radiosensitisation behavior reported in vitro for radioresistant cancer cells ${ }^{16}$ and an overproduction of hydroxyl radicals in water under X-ray irradiation $^{17}$; 4) the grafting of biomolecules through diverse functionalization strategies ${ }^{9,18,19}$; 5) specific fluorescence properties ${ }^{20}$. Until now, two different approaches were developed to hydrogenate DND: one involving a hydrogen microwave plasma ${ }^{9,21}$, the other, a thermal annealing under hydrogen ${ }^{22-24}$.

Despite recent progress in the understanding of hydrogenation treatment effects on the surface chemistry of $\mathrm{DND}^{11,7,6}$, the development of novel analytical tools allowing the identification of newly created bonds and a quantification of the hydrogen amount grafted at the surface or embedded in the diamond core remains challenging. For this purpose, the DND labelling using hydrogen isotopes appears as an attractive approach. On one hand, deuterium labelling can be used to study the hydrogen/surface interactions using Fourier-Transform InfraRed (FTIR) or Nuclear Magnetic Resonnance (NMR) spectroscopies. Both techniques can provide important information concerning the origin of the hydrogen-treated terminations present at the surface of DND and bring a better understanding of hydrogenation treatment outcome in terms of surface modification. Tritium incorporation, thanks to its radioactive properties, can be used for quantification purposes to determine the number of hydrogen-treated terminations and their locations (surface and core) ${ }^{25-27}$. Moreover, tritium-labeled ND are of great interest for the study of the in-vivo fate and more particularly the assessment of their toxicity, tissue distribution and elimination. One of the major challenge in the field of isotopically labelled nanoparticles synthesis resides in the development of reproducible and easy to implement synthetic protocols allowing the incorporation of isotopes without changing the surface properties in comparison with the hydrogen-treated analogues. In the case of tritium-treated ND, the two methods published so far, imply very high reaction temperatures and complex reaction set-ups. Nevertheless, in both cases, the characterization of the obtained radioactive analogues was incomplete. In the present work, we describe a robust and scalable method to control the deuterium and tritium incorporation in DND in a closed system using $\mathrm{D}_{2}$ or $\mathrm{T}_{2}$ gases. According to our knowledge, for the first time, isotopically labelled DND have been fully characterized and the isotope incorporation used to unravel the interactions between hydrogen-treated species and the nanomaterial.

\section{2) Results and discussion}

\subsection{Design and optimization of the thermal hydrogenation in a closed system}

Up to now, reported hydrogen annealing procedures of DND were performed under hydrogen gas flow. This experimental set-up allows notably to remove desorbed species from the reactive atmosphere which facilitate the surface hydrogenation. However, this approach can be considered as undesirable for the preparation of deuterium-treated DND (using expensive deuterium gas) and unreasonable in the context of the synthesis of tritium-treated DND (using radioactive tritium gas). Therefore, we have developed and optimized a new experimental approach to perform such thermal annealing using small gas volumes with no gas flow (see experimental section). To optimize the annealing procedure, we have monitored the formation of $\mathrm{C}-\mathrm{H}$ bonds and the decrease of C-O related groups using FTIR depending on the temperature, the gas pressure and the annealing time. 
Figure 1 shows FTIR spectra of as-received DND and DND treated at $450^{\circ} \mathrm{C}$ and $550^{\circ} \mathrm{C}$ under either 20 or 200 mbar of hydrogen for 1 hour. All spectra were normalized according to their fingerprints (around 1100-1200 $\mathrm{cm}^{-1}$ ). Samples were in-situ dried for at least $24 \mathrm{~h}$ under dry nitrogen. However, physisorbed water residues remain, leading to $\mathrm{O}-\mathrm{H}$ bending modes at $1630 \mathrm{~cm}^{-1}$ and O-H stretching modes located between 3000 and $3600 \mathrm{~cm}^{-1}$.

As-received DND exhibit a broad band around $1730-1790 \mathrm{~cm}^{-1}$ associated with $\mathrm{C}=\mathrm{O}$ stretching involved in carboxylic acid groups and anhydride functionalities (various types of surface carbonyl groups ${ }^{28}$ ). Between 900 and $1300 \mathrm{~cm}^{-1}$, a broad absorbance region is observed, usually attributed to diamond core defects and $\mathrm{C}-\mathrm{O}$ related groups, such as ether-like bonds or hydroxyl groups ${ }^{15}$. Finally, small features can be observed between 2800 and $3000 \mathrm{~cm}^{-1}$, attributed to C$\mathrm{H}$ stretching modes.

After annealing, even for the smoothest conditions, a shift of the band related to $\mathrm{C}=\mathrm{O}$ stretching modes occurs, down to $1710 \mathrm{~cm}^{-1}$, along with a decrease of its area. The direct comparison of peak intensities between these different spectra is rather difficult due to the presence of water residues and normalization issues. However, it seems obvious that the complete vanishing of the $\mathrm{C}=\mathrm{O}$ stretching modes is obtained only for the harshest conditions, i.e. $550^{\circ} \mathrm{C}$ and $200 \mathrm{mbar}$. The reduction of the $\mathrm{C}=\mathrm{O}$ related groups correlated with a modification of the $900-1300 \mathrm{~cm}^{-1}$ area attributed to the decrease of $\mathrm{C}-\mathrm{O}$ related groups.

At the same time, depending on the temperature and pressure, a modification of the $\mathrm{C}-\mathrm{H}$ stretching modes occurs. Starting from a specific signature of as-received samples related to surface hydrocarbons and disordered carbon, the shape of the $\mathrm{C}-\mathrm{H}$ modes progressively evolves up to a well-defined structure composed with two peaks located at 2875 and $2930 \mathrm{~cm}^{-1}$ related to symmetric and asymmetric $\mathrm{C}-\mathrm{H}$ stretching of $\mathrm{CH}_{\mathrm{x}}$ features ${ }^{28}$ (Figure 1). This $\mathrm{C}-\mathrm{H}$ signature is in agreement with the $\mathrm{C}-\mathrm{H}$ structures reported in the literature for ND treated under hydrogen flow $^{29,28}$. 


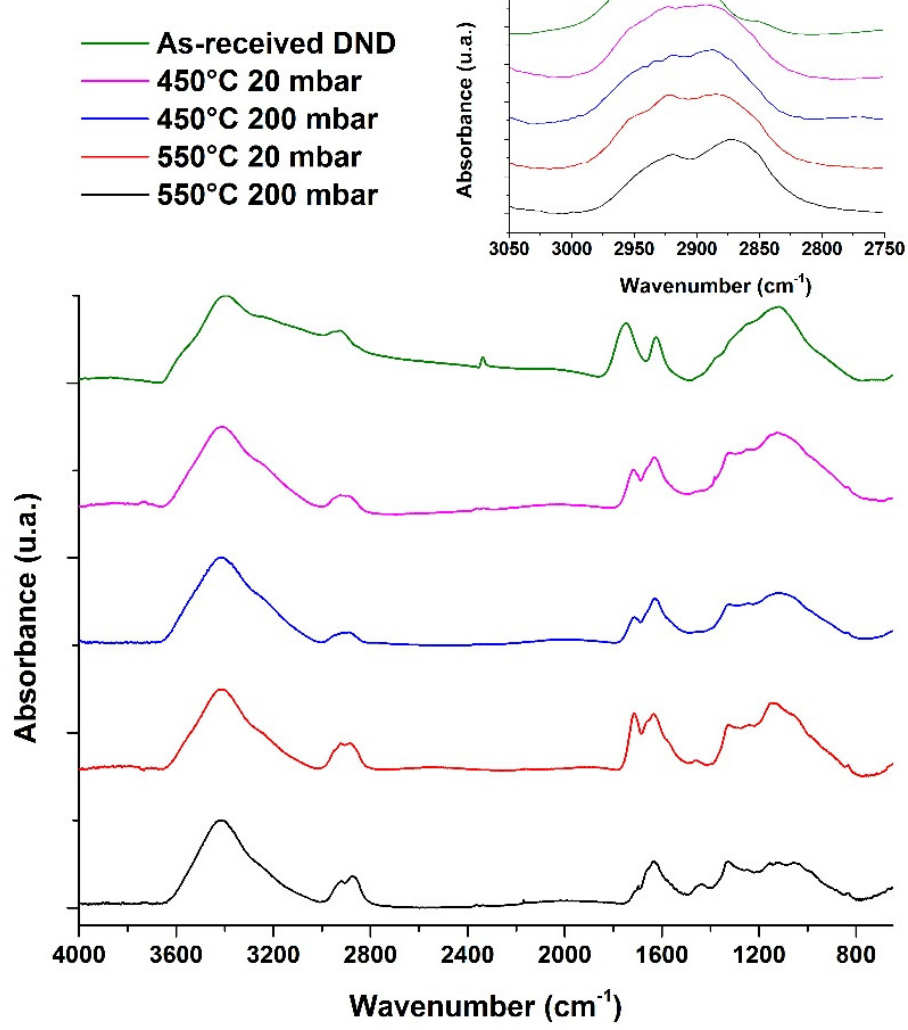

Figure 1: FTIR spectra of DND as-received and annealed under $\mathrm{H}_{2}$. Insert: Magnification of $\mathrm{C}-\mathrm{H}$ stretching modes. Spectra were normalized to the maximum absorbance.

To evaluate the carbon crystalline structure of DND after hydrogenation treatment, Raman spectroscopy was performed. Spectra of as-received and hydrogen-treated DND under $550^{\circ} \mathrm{C}$ at 200 mbar are plotted in Figure 2. Both spectra look very similar with a first order Raman mode of cubic diamond lattice observed near $1320 \mathrm{~cm}^{-1}$, in agreement with the signature of DND for which a phonon-confinement effect is observed ${ }^{30}$. In addition, a broad asymmetric contribution with a maximum lying at $1620 \mathrm{~cm}^{-1}$ could be assigned to the " $\mathrm{G}$ " band of carbon compounds. This "G" band on DND originates from the complex chemistry of the particle associating $\mathrm{sp}^{2}$ carbon signatures in different forms (fullerene like reconstructions, $\mathrm{sp}^{2}$ chains, etc.), lattice defects as well as some contributions of $\mathrm{C}-\mathrm{O}$ related groups ${ }^{31}$. Note that the intensity ratio of the diamond peak to the " $G$ " band is not modified by hydrogen annealing. The similarity of the Raman spectra confirms that hydrogenation treatment in these specific conditions alters neither the diamond core nor the surface carbon structure. Finally, the shoulder detected at $1500 \mathrm{~cm}^{-1}$ was previously reported on DND characterized by Raman using the same wavelength range ${ }^{31}$. 


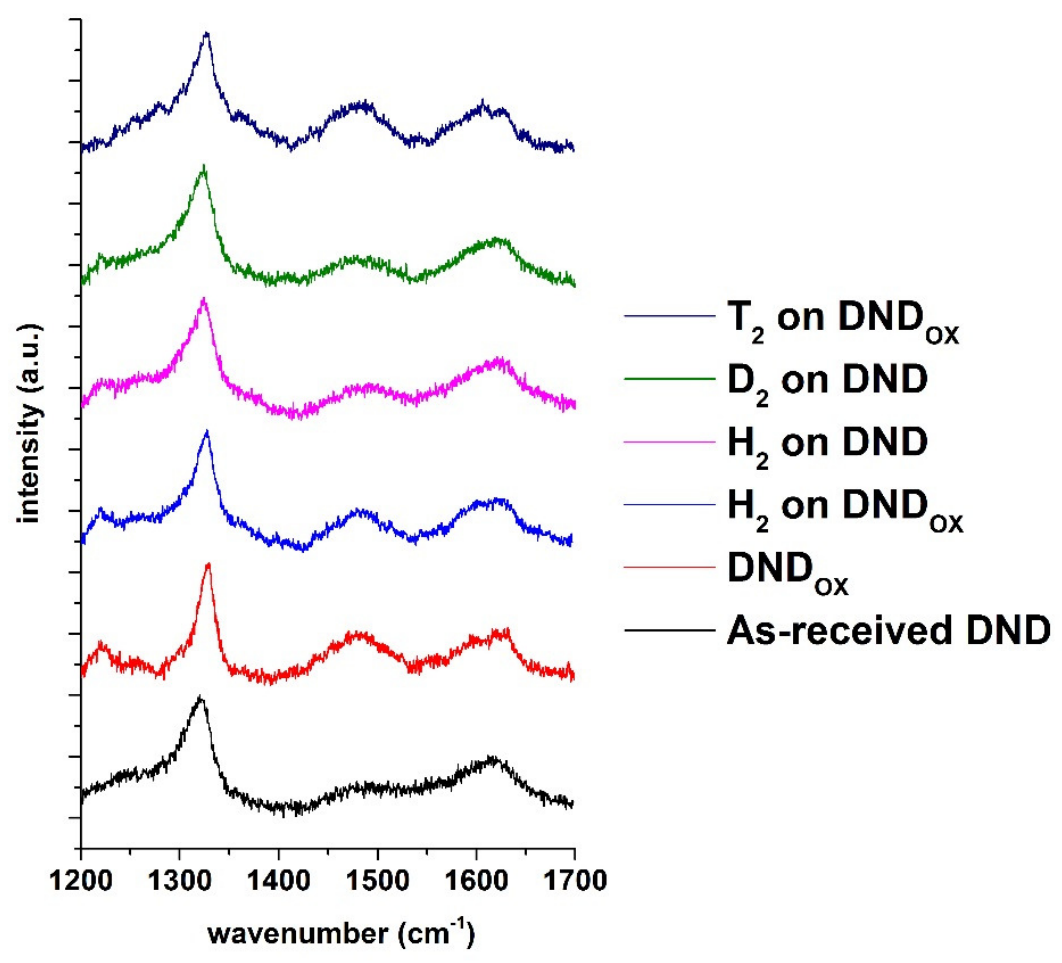

Figure 2: Raman spectra of as-received DND and DND 0 before and after annealing under different atmospheres. Laser excitation $532 \mathrm{~nm}$.

\subsection{Application to the preparation of deuterium-treated nanodiamonds}

We first apply our new thermal annealing protocol to the preparation of deuterium-treated DND. Beside this synthetic application of our new protocol, we thought that such labelling may be used to gain more insights onto the hydrogenation annealing of DND taking advantage of the large differences between $\mathrm{C}-\mathrm{H} / \mathrm{C}-\mathrm{D}$ stretching modes. The most efficient annealing conditions were used $\left(550^{\circ} \mathrm{C}, 200 \mathrm{mbar}, 1 \mathrm{~h}\right)$ with exactly the same experimental protocol using $\mathrm{D}_{2}$ gas instead of $\mathrm{H}_{2}$ gas.

FTIR spectrum of deuterium-treated sample is compared with hydrogen-treated particles prepared in the same conditions and as-received DND (Figure 3). As with hydrogen, under deuterium atmosphere, a complete reduction of $\mathrm{C}=\mathrm{O}$ related groups is evidenced with the disappearance of the band near $1730-1790 \mathrm{~cm}^{-1}$ on the FTIR spectrum. Furthermore, the appearance of a broad band near $2150 \mathrm{~cm}^{-1}$, associated with C-D ((i.e. C- $\left.{ }^{2} \mathrm{H}\right)$ stretching shows an effective deuteration of $\mathrm{DND}^{32}$. Surprisingly, the vibrations in the $2800-3000 \mathrm{~cm}^{-1}$ region associated with $\mathrm{C}-\mathrm{H}$ stretching are enhanced, with the appearance of the typical two peaks signature of hydrogen-treated DND. However, when normalized to the $1100-1200 \mathrm{~cm}^{-1}$ area, $\mathrm{C}-\mathrm{H}$ stretching modes of the deuterium-treated sample appears less intense than for the hydrogen-treated one. Nevertheless, this clear signature suggests the formation of hydrogen terminations on DND's surface while treatment was performed in pure $\mathrm{D}_{2}$ atmosphere. These C-H bonds may arise from native DND or from physisorbed species present on DND's surface.

Additionally, the Raman spectrum of deuterium-treated DND looks very similar to the one obtained for thermal hydrogenation exhibiting the first order Raman peak of diamond comparable to the one of as-received DND (Figure 2). 


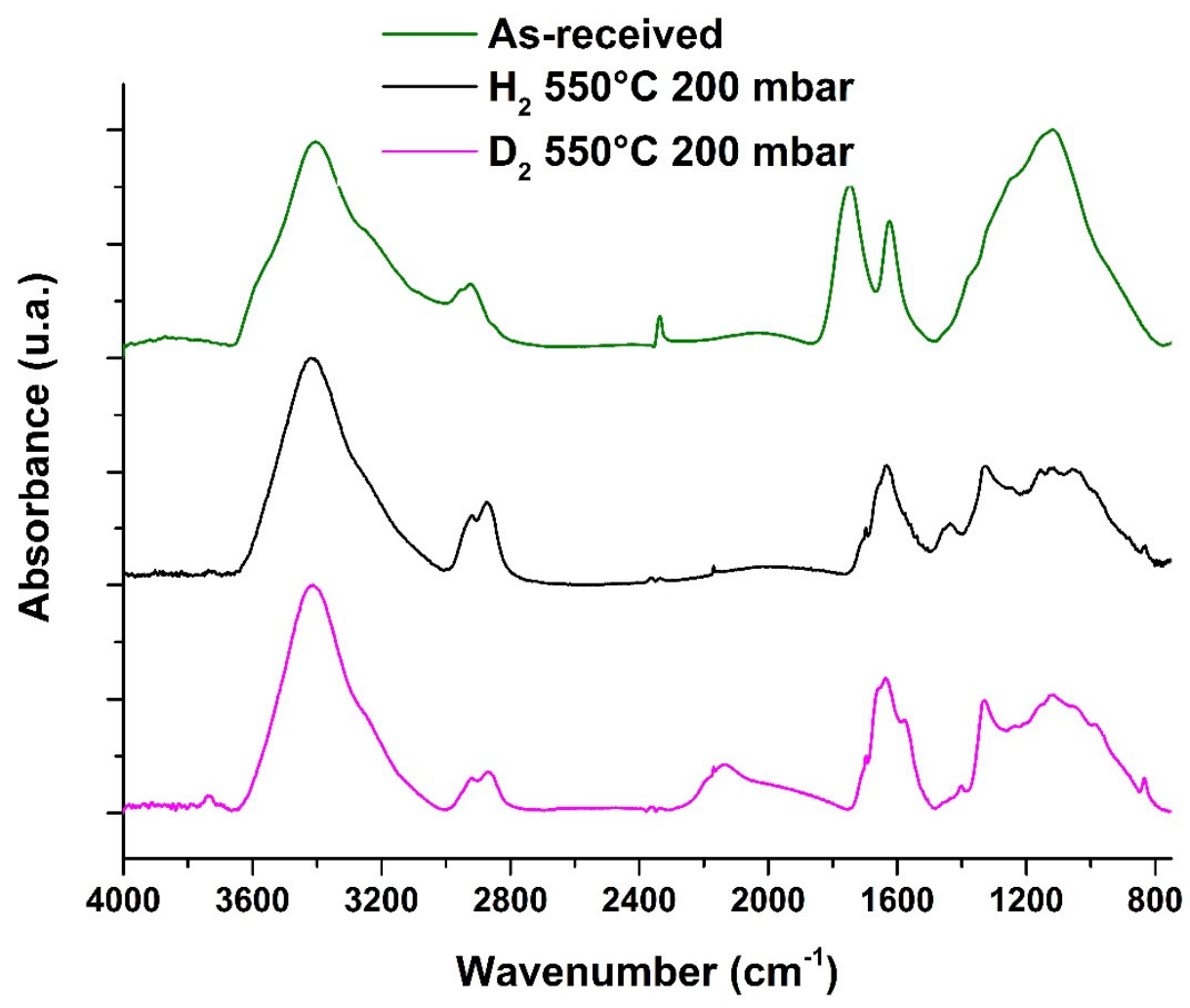

Figure 3: FTIR spectra of as-received, hydrogen-treated and deuterium-treated DND at $550^{\circ} \mathrm{C}$ and 200 mbar during $1 \mathrm{~h}$. Spectra were normalized to the maximum absorbance.

To investigate the origin of the hydrogen responsible for the creation of $\mathrm{C}-\mathrm{H}$ terminations in pure $\mathrm{D}_{2}$ atmosphere, two experiments were conducted. The first one consisted in the exposure of DND to pure $\mathrm{D}_{2}$ atmosphere in a larger volume to dilute the hydrogen species desorbed from the particles. The second experiment included a purge of the closed system between two $\mathrm{D}_{2}$ treatments. FTIR spectra and absorbance ratios calculated from $\mathrm{C}-\mathrm{D}$ and $\mathrm{C}-\mathrm{H}$ stretching modes are presented on Figure 4 and Table 1, respectively. In both cases, creation of C-D bonds appears more effective, compared to the simple $\mathrm{D}_{2}$ treatment in small volume without intermediate purge. Finally, when a pretreatment of DND under argon atmosphere at $350^{\circ} \mathrm{C}$ is applied just before $\mathrm{D}_{2}$ annealing, no reduction of the amount of $\mathrm{C}-\mathrm{H}$ created is seen, which seems to exclude water residues as the source of hydrogen. 


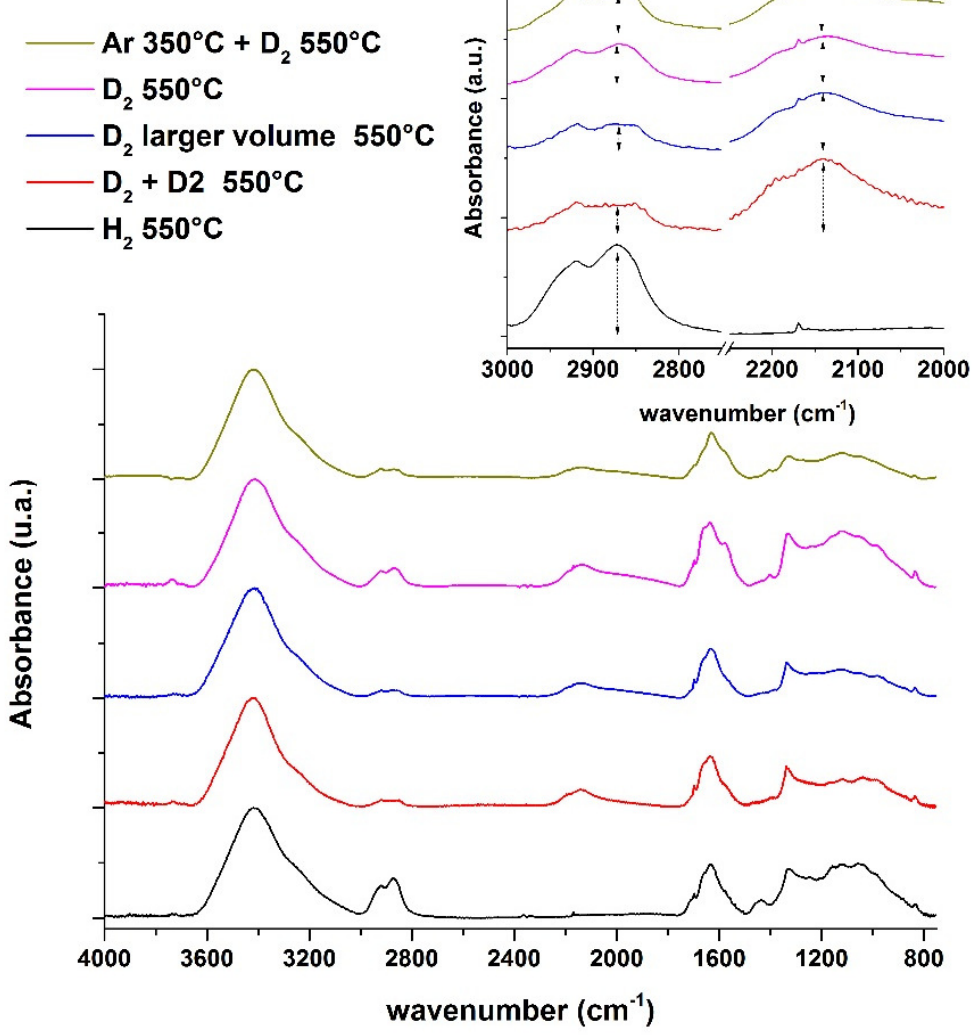

Figure 4: FTIR spectra and magnification in $2000-3000 \mathrm{~cm}^{-1}$ range for hydrogen-treated and deuterium-treated DND in different conditions (200 mbar, 1h). Spectra were normalized to the maximum absorbance.

Table 1: Absorbance ratio R of C-D to C-H stretching modes located at 2140 and $2870 \mathrm{~cm}^{-1}$

\begin{tabular}{|c|c|}
\hline Treatment & Ratio C-D /C-H \\
\hline $\mathrm{H}_{2} 550^{\circ} \mathrm{C} 200 \mathrm{mbar}$ & 0 \\
\hline $\mathrm{D}_{2} 550^{\circ} \mathrm{C} 200 \mathrm{mbar}$ & 1.2 \\
\hline $\mathrm{D}_{2}$ larger volume & 2 \\
\hline $\mathrm{D}_{2} /$ purge $/ \mathrm{D}_{2} 550^{\circ} \mathrm{C} 200 \mathrm{mbar}$ & 2.3 \\
\hline $\mathrm{Ar} 350^{\circ} \mathrm{C} /$ purge $/ \mathrm{D}_{2} 550^{\circ} \mathrm{C} 200 \mathrm{mbar}$ & 1.2 \\
\hline $\mathrm{D}_{2} 550^{\circ} \mathrm{C} 200 \mathrm{mbar}$ on $\mathrm{DND}$ OX & 2.3 \\
\hline
\end{tabular}

\subsection{Hydrogenation and deuteration of pre-oxidized DND}

To confirm that the hydrogen initially present at the surface of DND can be involved in the hydrogenation process, as-received DND were cleaned by a thermal oxidation step. Indeed, such surface treatment induces the removal of non-diamond carbon, a better homogenization of oxygen groups with more numerous carboxylic groups according to Boehm titration ${ }^{33}$ and provide a better colloidal stability in aqueous suspensions with a negative Zeta potential ${ }^{34}$.

As-received DND were oxidized in a furnace for $1 \mathrm{~h} 30$ at $550^{\circ} \mathrm{C}$ leading to air oxidized DND (DNDox). Note that the diamond core is preserved, as shown by the Raman spectrum (Figure 2). The FTIR spectrum still shows a well-defined band located at $1730-1790 \mathrm{~cm}^{-1}$ 
assigned to $\mathrm{C}=\mathrm{O}$ bonds (Figure 5) as well as an almost complete vanishing of the $\mathrm{C}-\mathrm{H}$ stretching modes between 2800 and $3000 \mathrm{~cm}^{-1}$.

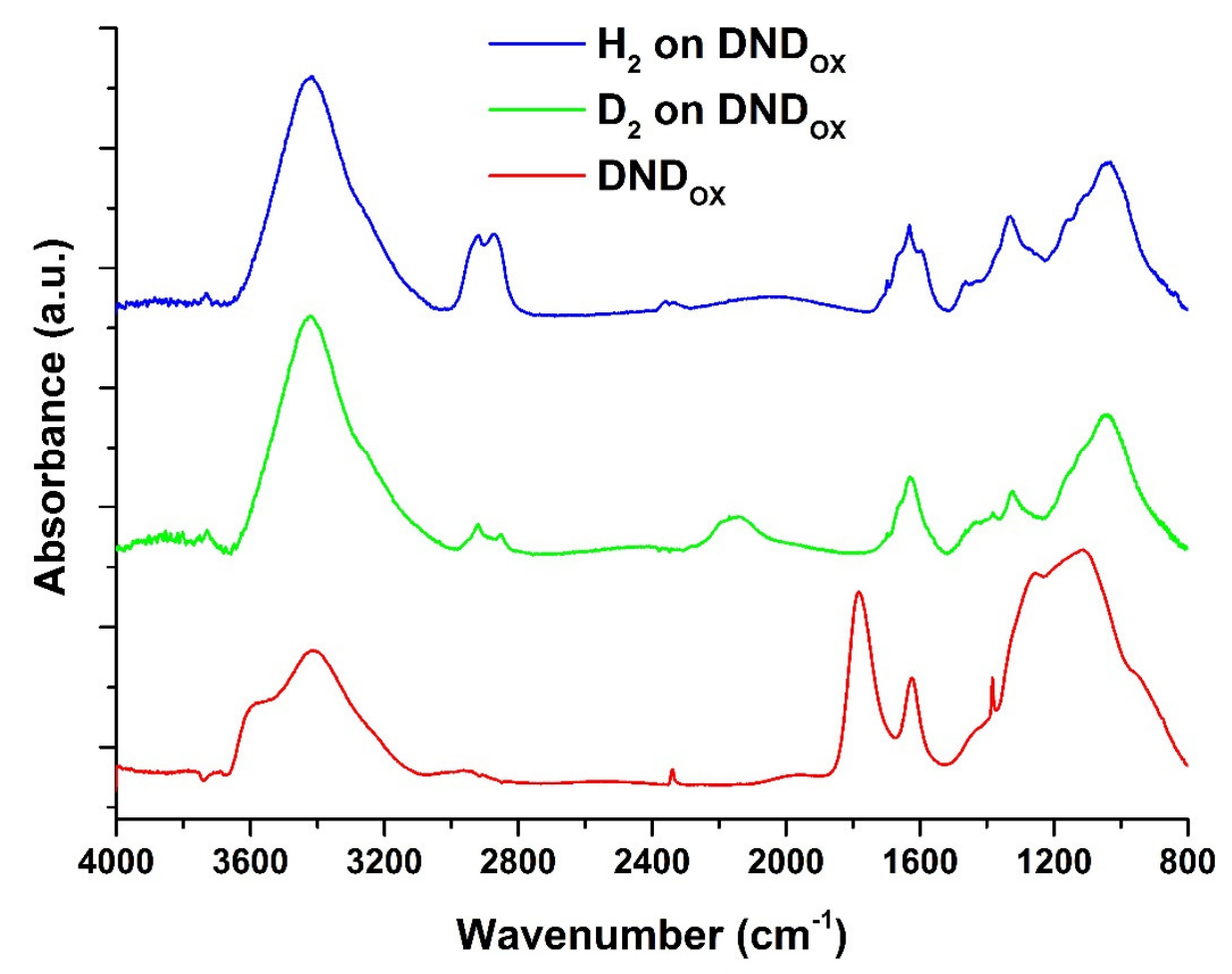

Figure 5: FTIR spectra of $\mathrm{DND}_{\mathrm{OX}}$, hydrogen-treated $\mathrm{DND}_{\mathrm{OX}}$ and deuterium-treated $\mathrm{DND}_{\mathrm{OX}}$. Hydrogenation and deuteration were performed during $4 \mathrm{~h}$ at $550^{\circ} \mathrm{C}$ and $200 \mathrm{mbar}$. Spectra were normalized to the $1100-1200 \mathrm{~cm}^{-1}$ band.

After annealing under hydrogen for $1 \mathrm{~h}\left(550^{\circ} \mathrm{C}, 200 \mathrm{mbar}\right)$, the FTIR spectrum indicates only a partial reduction of the $\mathrm{C}=\mathrm{O}$ groups at the surface. Therefore, on these oxidized DND, a longer thermal hydrogenation is needed (up to $4 \mathrm{~h}$ ), to fully remove the $\mathrm{C}=\mathrm{O}$ related bands around $1730-1790 \mathrm{~cm}^{-1}$ (Figure 5). The same behavior occurred for deuterium annealing (Figure 5).

Different hypotheses can be made to explain this slower kinetic compared to as-received DND. First, the nature of the oxygen-related groups present at the DND surface may be modified by annealing under air with the creation of anhydrides for instance. Indeed, the maximum intensity peak of the $\mathrm{C}=\mathrm{O}$ stretching mode is shifted from $1750 \mathrm{~cm}^{-1}$ to $1780 \mathrm{~cm}^{-1}$ after air annealing, which is in agreement with anhydrides formation ${ }^{35}$. As a second hypothesis, the amount of oxygen-related groups may be higher after air annealing. However, no reliable quantitative information can be extracted from FTIR spectroscopy. It can only be noticed that, according to the spectra, the ratio between the fingerprint area $\left(1100-1200 \mathrm{~cm}^{-1}\right)$ and the $\mathrm{C}=\mathrm{O}$ stretching mode remain rather similar before and after air annealing. Finally, based on the mechanism proposed by Cheng and Williams ${ }^{6}$, we can consider that the amount of $\mathrm{C}_{3}$ species at the origin of the catalytic process (enabling the $\mathrm{H}_{2}$ dissociation) may be strongly affected by air annealing. Indeed, such carbon species can be efficiently etched during this annealing. 
Concerning C-H stretching modes, hydrogen-treated DND $\mathrm{Ox}$ exhibit enhanced vibrations in the 2800-3000 $\mathrm{cm}^{-1}$ region (Figure 5) comparable to hydrogen-treated as-received DND (Figure 4). When treated under deuterium, the broad band near $2150 \mathrm{~cm}^{-1}$, associated with C-D stretching confirms an effective deuteration of DND. At the same time, $\mathrm{C}-\mathrm{H}$ stretching modes are still visible on the FTIR spectrum, which suggests the creation of some $\mathrm{C}-\mathrm{H}$ terminations on these strongly oxidized DND. However, the phenomenon remains limited with a C-D/C-H ratio R of 2.3 (Table 1). The oxidation treatment is thus an efficient way to better control the amount of $\mathrm{C}-\mathrm{H}$ bonds generated during thermal hydrogenation. The quantification of tritium-treated DND will allow an estimation of the hydrogen coverage.

\subsection{Colloidal behavior of hydrogen-treated and deuterium-treated DND}

Colloidal properties of hydrogen-treated and deuterium-treated as-received DND and DNDox suspended in water were measured by Dynamic Light Scattering (DLS) (see Figure S1). Hydrogen-treated as-received DND and DND $_{\mathrm{Ox}}$ exhibit similar hydrodynamic mean diameter around $35 \mathrm{~nm}$. The Zeta potential are also very close, with a charge of $+45 \pm 5 \mathrm{mV}$ when asreceived DND are hydrogen-treated versus $+53 \pm 1 \mathrm{mV}$ when $\mathrm{DND}_{\text {ox }}$ are hydrogen-treated. We can conclude here that the oxidizing pre-treatment does not seem to affect the final colloidal properties (while DND $\mathrm{OX}_{\mathrm{X}}$ exhibited a strong negative Zeta potential of $-57 \pm 5 \mathrm{mV}$ ). These positive Zeta potentials are in line with reported studies dealing with hydrogen-treated DND whatever the hydrogenation method (annealing ${ }^{13}$ or plasma ${ }^{11}$ ). Its origin is still under debate, according to spectroscopic investigations, it may imply the interactions with surrounding water molecules ${ }^{14,15,24}$.

Such independence from the initial surface chemistry was also observed for deuterium-treated DND, which exhibits a rather constant hydrodynamic mean diameter around $30 \mathrm{~nm}$, whatever the initial powder (see Figure S1) and Zeta potentials in the same range of $+38 \mathrm{mV}$ to $+51 \mathrm{mV}$. More generally, colloidal properties of hydrogen-treated and deuterium-treated DND in water look very similar with or without the oxidation pretreatment. Covering the DND surface with hydrogen or deuterium does not seem to affect the interactions with water, at least not sufficiently to de-stabilize the particles. Note that this ability of deuterium-treated DND to be suspended in water the same way the hydrogen-treated DND may open the door to more advanced structural studies, toward better understanding of the water/DND interface.

\subsection{Thermal and plasma tritiation}

Going further in the use of hydrogen isotopes to investigate the hydrogenation process of DND, tritium was used instead of hydrogen in our closed system. The use of tritium permits to assess the amount retained by DND thanks to liquid scintillation counting. Indeed, an important question emerges in the literature concerning the hydrogen amount which can be bonded to DND depending on methods or on experimental conditions ${ }^{7}$.

Tritiation of DND was performed on as-received DND and on oxidized ones using annealing procedures described above. To complete the study, as-received DND were also reduced using the plasma labeling method previously reported ${ }^{25}$ as a comparison with our previous works. 
Raman spectrum of tritium-treated DNDox (Figure 2) exhibits a comparable signature than those obtained after hydrogen or deuterium treatments (in the same experimental conditions). It clearly shows the non-alteration of the diamond core.

Quantification of the tritium incorporation was assessed by measuring the radioactivity in the combustion gas of tritium-treated DND heated in air using liquid scintillation counting. Regarding the quantification of the tritium atoms bonded to the DND surface, the specific activity was first measured by performing a complete combustion of the tritium-treated DND under air for $3 \mathrm{~h}$ at $600^{\circ} \mathrm{C}$. Exposed to a pure tritium atmosphere, the specific activity is 9 times higher compared to plasma-treated DND, i.e. $154 \mathrm{mCi} . \mathrm{mg}^{-1}$ compared to $17 \mathrm{mCi}^{\mathrm{mg}}{ }^{-1}$ (Table 2 ). Note that the specific activity measured here for plasma treatment is in the same range than the one reported previously for a plasma treatment but using another DND source ( 9 mCi.mg$\left.{ }^{1}\right)^{25}$. To explain the difference between annealed and plasma-treated DND, we need to consider the applied pressures used, i.e. 200 mbar for annealing and 12 mbar for plasma treatment. However, a difference in terms of surface reactivity and hydrogen radical production mechanisms cannot be excluded.

Annealing under a tritium atmosphere was also conducted on DNDox. To obtain comparable results in terms of specific activity regarding the plasma treated DND, the tritium concentration was lowered to $10 \%$ of the total atmosphere during annealing, the $90 \%$ remaining being composed of pure $\mathrm{H}_{2}$. Taking into account the ${ }^{3} \mathrm{H}_{2} /{ }^{1} \mathrm{H}_{2}$ ratio in the gas phase, a comparable specific activity is measured, i.e. $13 \mathrm{mCi}^{\mathrm{mg}} \mathrm{m}^{-1}$. It thus appeared that the amount of bonded tritium can be efficiently tuned by lowering the tritium concentration in the gas phase during the annealing process.

Table 2: Total radioactivity measured by liquid scintillation counting for plasma and annealed DND (as-received or pre-oxidized). Two tritium concentrations were used.

\begin{tabular}{|cccc|}
\hline Treatment & DND & ${ }^{\mathbf{3}} \mathbf{H}_{2} \mathbf{( \% )}$ & $\begin{array}{c}\text { Specific } \\
\text { activity } \\
\left(\mathbf{m C i}^{-1} \mathbf{)}\right)\end{array}$ \\
\hline Plasma & as-received & 100 & 17 \\
Annealing & as-received & 100 & 154 \\
Annealing & oxidized & 10 & 13 \\
\hline
\end{tabular}

To identify and quantify the different tritium binding states, the radioactivity counting was performed at several desorption isotherms during one hour for each $\left(20^{\circ} \mathrm{C}, 200^{\circ} \mathrm{C}, 400^{\circ} \mathrm{C}\right.$, $600^{\circ} \mathrm{C}$ ). The radioactivity released from $3 \mathrm{mg}$ of tritium-treated DND by annealing according to the different temperature thresholds is reported in Table 3.

Table 3: Radioactivity distribution of tritium released from $3 \mathrm{mg}$ tritium-annealed DND according to different temperature thresholds with 1 hour of stabilization. Note that two tritium concentrations were used.

\begin{tabular}{|c|c|c|}
\hline Temperature $\left({ }^{\circ} \mathbf{C}\right)$ & $\begin{array}{c}\text { as-received DND } \\
\text { using } \mathbf{1 0 0} \% \text { tritium }\end{array}$ & $\begin{array}{c}\text { oxidized DND } \\
\text { using } \mathbf{1 0} \% \text { tritium }\end{array}$ \\
\hline $\mathbf{2 0}$ & - & - \\
\hline $\mathbf{2 0 0}$ & $8 \%$ & $5 \%$ \\
\hline $\mathbf{4 0 0}$ & $72 \%$ & $83 \%$ \\
\hline
\end{tabular}




\begin{tabular}{|c|c|c|}
\hline $\mathbf{6 0 0}$ & $20 \%$ & $12 \%$ \\
\hline $\begin{array}{c}\text { Total activity measured from } \\
\text { thermodesorption studies (mCi) }\end{array}$ & 463 & 40 \\
\hline
\end{tabular}

Regarding the two DND, no significant tritium desorption was observed at room temperature. For tritium-treated as-received DND, after 1 hour at $200^{\circ} \mathrm{C}$, a weak amount of $35 \mathrm{mCi}$ was measured in the combustion gas representing $8 \%$ of the total radioactivity. At this stage, desorption only affects the tritium species weakly bonded to the DND surface (electrostatic adsorption, hydrogen bonds). After one hour at $400^{\circ} \mathrm{C}, 332 \mathrm{mCi}$ were released corresponding to $72 \%$ of the total radioactivity. At the later temperature threshold, a strong oxidation occurs with the formation of carbonyls and carboxylic groups and covalent surface terminations are desorbed ${ }^{35}$. Accordingly, the major part of tritium labeling is associated with ${ }^{3} \mathrm{H}$ strongly bonded at the DND surface. After the final threshold at $600^{\circ} \mathrm{C}$, the measured total activity is $131 \mathrm{mCi}$ which means that $20 \%$ of radioactivity remains in the diamond lattice. This result indicates a possible diffusion mechanism of tritium into the diamond cores of DND or in their embedded defects made of disordered graphitic carbon. This mechanism was previously demonstrated for hydrogen and deuterium into bulk diamond ${ }^{36}$ while using higher annealing temperatures. These results also show that tritium labeling of DND using an annealing pathway is very efficient. The high specific activity of $154 \mathrm{mCi}^{\mathrm{mg}} \mathrm{g}^{-1}$ significantly exceeds standards regarding biodistribution studies ${ }^{37}$.

Radioactivity values collected during the same temperature thresholds for tritium-treated DND $_{\text {Ox }}$ are in the same range as the values obtained for DND (Table 3). After a first annealing at $200^{\circ} \mathrm{C}, 2 \mathrm{mCi}$ (i.e. $5 \%$ of the total radioactivity) was measured. After one hour at $400^{\circ} \mathrm{C}$, $33 \mathrm{mCi}$ was released corresponding to $83 \%$ of the total radioactivity. After the final threshold at $600^{\circ} \mathrm{C}$, the total activity released is $40 \mathrm{mCi}$. The radioactivity collected during the last annealing represents $12 \%$ of this value.

A similar proportion of radioactivity is measured for weakly bonded tritium for both tritium annealing ( $8 \%$ and $5 \%)$. Nevertheless, the amount of tritium covalently bonded at DND surface increases significantly $(+11 \%)$ for pre-oxidized DND leading to less tritium located in the diamond core (12\% compared to $20 \%$ ). This lower value can be explained by the fact that $10 \%$ of tritium only is present in the gas atmosphere and is available for diffusion in diamond lattice.

This tritium repartition is consistent with our previous work on tritium-treated DND by microwave plasma ${ }^{25}$. In that case, $7 \%$ of the tritium was located in the diamond core and $83 \%$ covalently bonded at the surface. At that time, using the developed surface area and the activity, we estimated that 1 carbon atom over 20 was susceptible to be linked to a tritium atom. Here, using the annealing treatment, we can suggest that the tritium coverage is close to $50 \%$. These results demonstrate that our new protocol can be used for the preparation of tritium-treated DND with tunable specific activities, which is crucial for future biodistribution and pharmacokinetics studies of such largely applied nanoparticles.

Finally, tritium-treated DNDox were suspended in water using a protocol similar to the one used for hydrogen-treated and deuterium-treated DND. DLS measurement (see Figure S1) reveals a colloidal behavior with a mean hydrodynamic diameter close to $15 \mathrm{~nm}$, which is slightly smaller than for hydrogen-treated and deuterium-treated DND. Anyway, this result open the door to further biological experiments, where the stability of tritium-treated DND is a pre-requisite. 


\subsection{NMR investigations of hydrogen-treated, deuterium-treated and tritium-treated DND}

The previous DND annealed under hydrogen, deuterium or tritium atmosphere were then studied by Magic Angle Spinning (MAS) NMR to better investigate the nature of the carbon structure and the $\mathrm{C}-\mathrm{H}$ bonds ${ }^{38,39}$.The ${ }^{13} \mathrm{C}$ MAS NMR spectra are shown in Figure 6a for hydrogen-treated and deuterium-treated DND (with or without pre-oxidation). Dashed lines highlight the positions of the three main peaks observed, in agreement with previous studies ${ }^{38-}$ ${ }^{42}$. The most intense one, located at around $34 \mathrm{ppm}$, is generally assigned to carbon atoms that are in the DND crystalline core (narrow component of the peak) and in the shell near the surface that covers the diamond core. This main peak is observed whatever the DND, confirming the persistence of a diamond core revealed by Raman spectroscopy (Figure 2). A second narrow resonance at a lower chemical shift (here $28 \mathrm{ppm}$ ) appears but the assignment of this band is still unclear (see a short discussion in Panich et al. paper $^{39}$ and references therein). A third broad shoulder centered at $\sim 45 \mathrm{ppm}$ is generally assigned to hydrogen-treated surface species $(\mathrm{CH}$ and $\mathrm{CH}_{2}$ ). So far, with these ${ }^{13} \mathrm{C}$ MAS spectra, no clear distinctions can be made between the different surface chemistries.
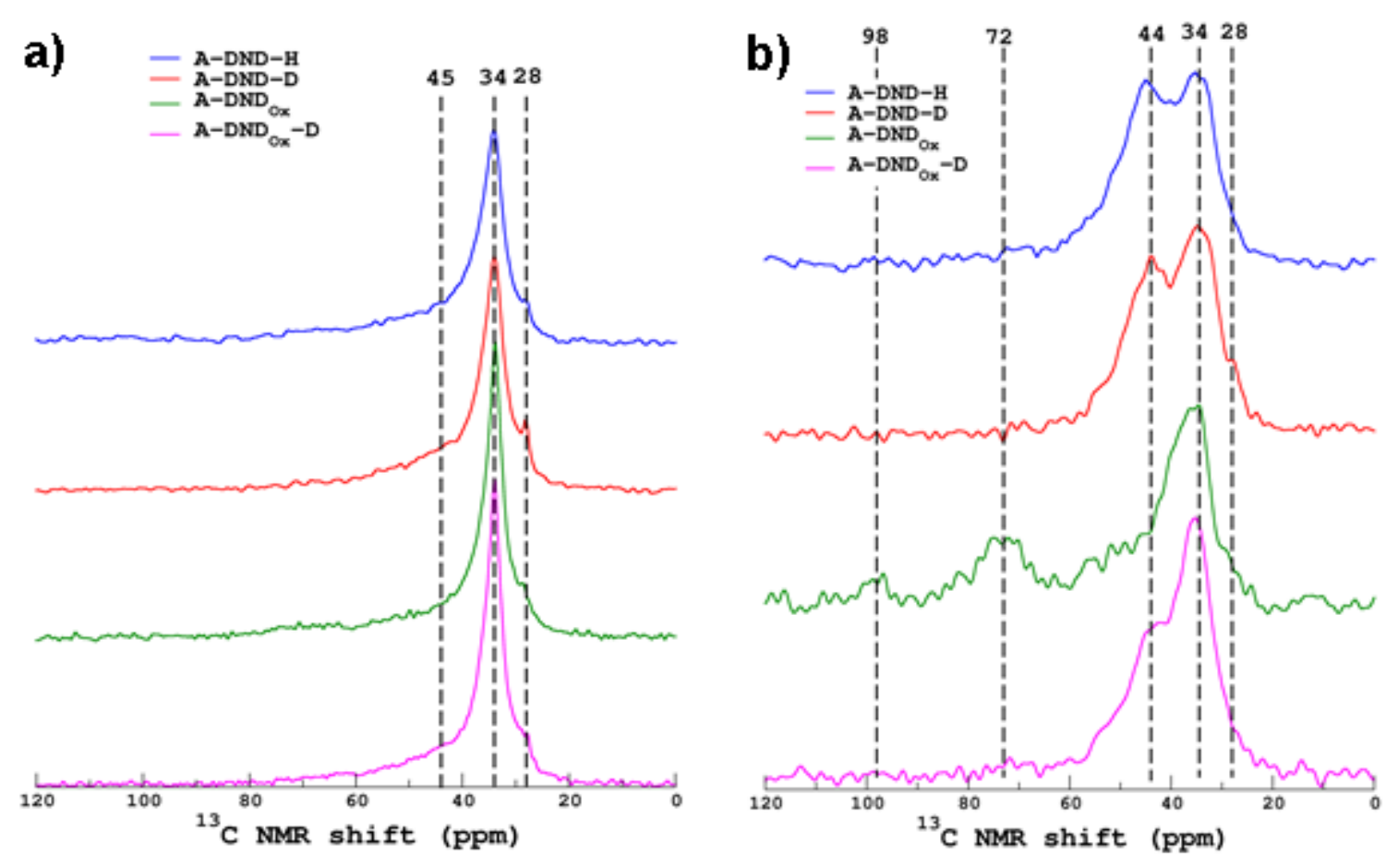

Figure 6 a) ${ }^{13} \mathrm{C}$ MAS NMR spectra of hydrogen-treated (A-DND-H), oxidized (A-DNDox) and deuterium-treated (A-DND-D) as-received DND and deuterium-treated preoxidized (ADND $\left._{\text {Ox }}-\mathrm{D}\right)$. b) ${ }^{13} \mathrm{C}$ CPMAS NMR spectra of the four investigated DND. Dashed lines highlight the main peaks. Spectra are normalized to the same area.

Therefore, to enhance the signal from the surface carbon atoms near proton atoms, ${ }^{13} \mathrm{C} /{ }^{1} \mathrm{H}$ Cross Polarization MAS (CPMAS) experiments were performed (Figure 6b) with a contact time of $2 \mathrm{~ms}$ (this period controls the length scale of the magnetization transfer from the protons to the carbons, see below) for which a maximum of ${ }^{13} \mathrm{C}$ signal was observed. A close examination of the line shape of those CPMAS spectra shows that the peak at $34 \mathrm{ppm}$ is broader than the one in direct acquisition spectra. This suggests that the bulk carbon sites characterized by a narrow 
peak are too far from the protons to be cross-polarized (i.e. magnetized) and has been therefore filtered out by the CPMAS sequence. This peak is now dominated by the carbon in the inner shell close to the hydrogen-treated species at $44 \mathrm{ppm}$ which are more efficiently excited by the $\mathrm{CP}$ process (at short CP times, the peak at $44 \mathrm{ppm}$ is stronger than the one at $34 \mathrm{ppm}$ ). This was clearly shown in the detailed NMR study of Fang et al. ${ }^{38}$ and also observed for our samples (see for example CPMAS spectra acquired at variable contact times for A-DND-H in the supplementary materials, Figure S2). Now, if we compare the different surface chemistries, this contribution at $44 \mathrm{ppm}$ is observed for hydrogen-treated DND but also for deuterium-treated DND and DNDox, while almost absent on oxidized DND. This is in agreement with FTIR experiments, also revealing $\mathrm{C}-\mathrm{H}$ stretching modes on all samples except DNDox. If we consider the 34 and 44 ppm components, CPMAS experiments tend to show also a weaker proportion of $\mathrm{C}-\mathrm{H}$ on deuterium-treated DNDox. The component at 72 and $98 \mathrm{ppm}$ on DNDox sample is assigned to $\mathrm{C}-\mathrm{OH}$ groups and other more oxidized groups ${ }^{43}$.

${ }^{2}$ H MAS NMR spectra collected on deuterium-treated DND and DNDox samples are shown in Figure 7. The center band (see insert) is around $1.8 \mathrm{ppm}$, which correspond to aliphatic protons that we can assign to $\mathrm{C}$-D terminations. This position nicely matches the value observed for the same samples on ${ }^{1} \mathrm{H}-{ }^{13} \mathrm{C}$ 2D HETCOR spectrum (see Figure S3), also exhibiting ${ }^{1} \mathrm{H}-\mathrm{C}$ contributions at $1.8 \mathrm{ppm}$ and coming from residual hydrogen reacting during deuterium treatment. Note that this low value seems specific to our treated DND and therefore to $\mathrm{C}-\mathrm{H}$ terminations, while literature reports on $3.8 \mathrm{ppm}$ protons for untreated samples ${ }^{38}$. But note that in our samples ${ }^{2} \mathrm{H}$ peak shows a tail extending up to $5 \mathrm{ppm}$ (insert figure S4). Quadrupolar spinning sideband manifold of both samples could be nicely fitted using a quadrupolar coupling constant of $170 \mathrm{kHz}$ and asymmetry parameter of 0.1 , values typical of a $\mathrm{C}-\mathrm{H}$ bond (see Figure S5).

Finally, comparison between ${ }^{3} \mathrm{H}$ and ${ }^{2} \mathrm{H}$ (center band only) MAS NMR for tritium-treated and deuterium-treated pre-oxidized DND is shown in Figure 8. Both spectra are centered on the same chemical shift region around $1.8 \mathrm{ppm}$. All these results confirm the suitability to compare ${ }^{1,2,3} \mathrm{H}$ treatments as all of them lead to similar $\mathrm{C}-{ }^{1,2,3} \mathrm{H}$ creation.

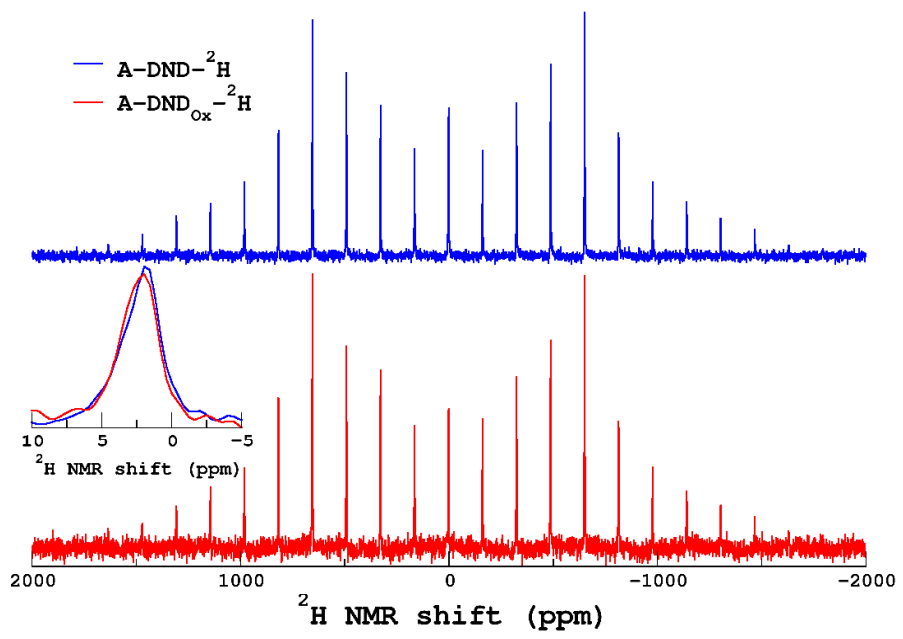

Figure $7{ }^{2} \mathrm{H}$ MAS NMR spectra of deuterium-treated DND (A-DND-D) and deuteriumtreated $\mathrm{DND}_{\mathrm{OX}}\left(\mathrm{A}-\mathrm{DND} \mathrm{Ox}_{\mathrm{Ox}}-\mathrm{D}\right)$. 


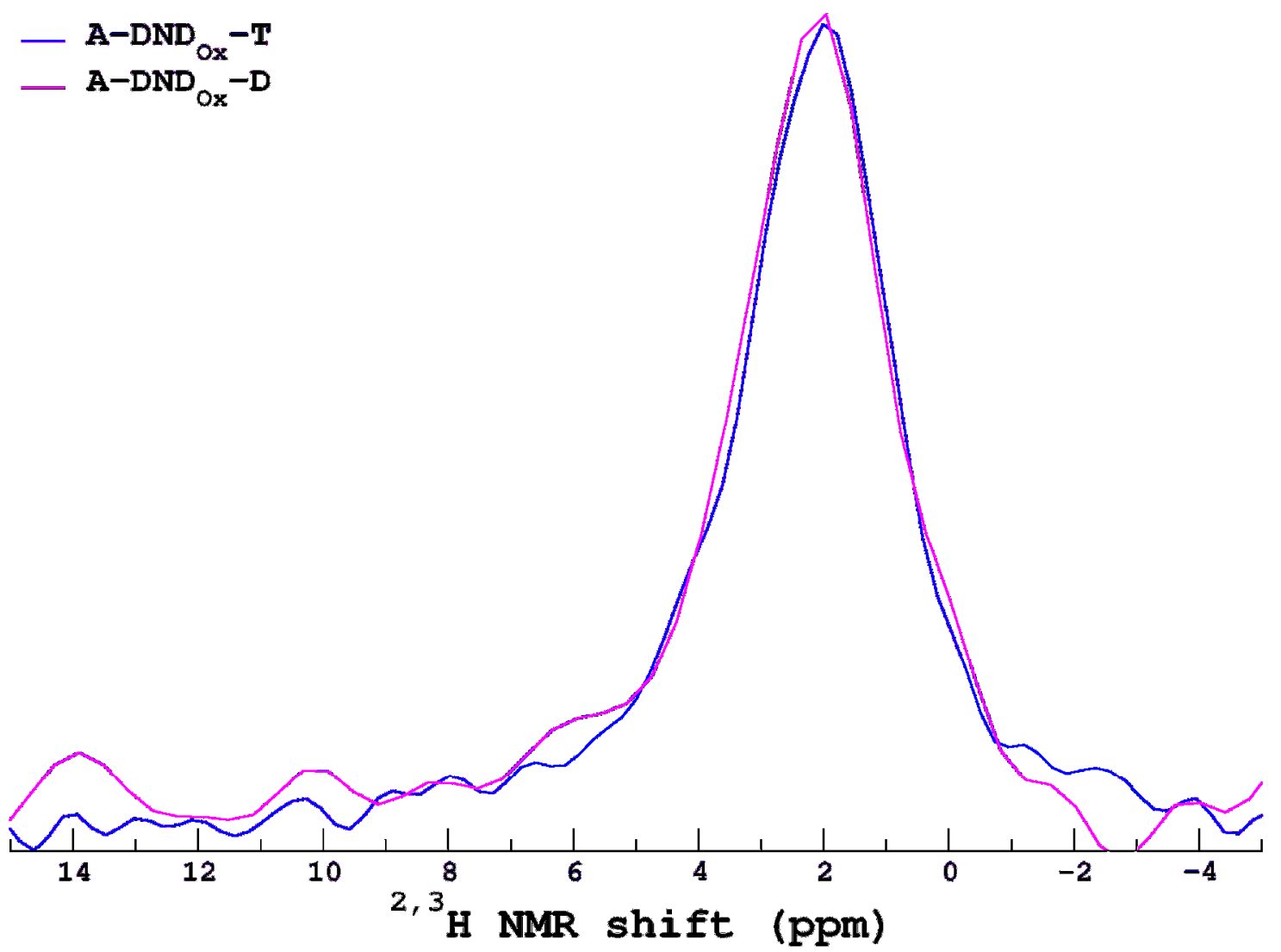

Figure 8: ${ }^{2} \mathrm{H}$ MAS NMR spectrum of deuterium-treated DNDox (A-DND ox $\left.^{-D}\right)$ and ${ }^{3} \mathrm{H}$ MAS NMR spectrum of tritium-treated DND $0 x\left(A-D D_{o x}-T\right)$.

\section{3) Conclusions}

The present study was conducted on DND using hydrogen and its isotopes $\left({ }^{2} \mathrm{H},{ }^{3} \mathrm{H}\right)$ via an annealing reduction method. This surface treatment was first optimized for hydrogenation in a closed set-up leading to a total reduction of $\mathrm{C}=\mathrm{O}$ bonds and the formation of $\mathrm{C}-\mathrm{H}$ terminations. It was further adapted to deuterium and tritium atmosphere leading to C-D and C-T creation at the surface of DND, as confirmed by FTIR and NMR experiments. NMR and Raman investigations demonstrated that the DND diamond core remain unaffected after annealing under hydrogen, deuterium and tritium. Raman also permits to confirm that no enhanced surface graphitization occurs after treatment. From experiments with deuterium, we have shown that residual hydrogen from DND is also active for $\mathrm{C}-\mathrm{H}$ formation under annealing. Such crossreaction can be limited by a preoxidation of DND. Nevertheless, it reveals the importance of the initial surface chemistry for such annealing treatments, which can participate to the reaction mechanism. Quantifications were assessed from tritium labeling of DND. As for plasma treatment, the major part of tritium is strongly bonded at DND surface while a non-negligible part diffuses inside the diamond core. Surprisingly, the annealing method led to ten times more tritium bonded to DND compared to plasma one. Interestingly, the specific activity of the radiolabeled DND can be easily tuned by playing with the initial $\mathrm{H}_{2} / \mathrm{T}_{2}$ ratio in the gas phase. Moreover, the labeling efficiency can be tuned adjusting the tritium concentration in hydrogen. Resulting colloidal aqueous suspensions possess similar properties compared to hydrogen- 
treated and deuterium-treated DND. Thus, isotopic labelling appears to be a powerful tool to better understand DND surface chemistry. It could be very useful to investigate their interactions with surrounding molecules in colloids, especially interactions with water molecules which appear specific for hydrogen-treated $\mathrm{DND}^{15}$ and may be involved in radical overproduction under irradiation ${ }^{17}$. Annealing using isotopes could be further adapted to other nanomaterials to investigate their surface properties for applications in nanomedicine or catalysis.

\section{4) Materials and Methods}

Tritium $\left(\mathrm{T}_{2}\right)$ was purchased from TRITEC (purity 99\%). $\mathrm{H}_{2}$ and $\mathrm{D}_{2}$ of a high-purity grade $(99.999 \%)$ were purchased from Air product and Eurisotop respectively. MiliQ water was obtained after purification on a Milipore systeme (resistivity $18 \mathrm{~m} \Omega$ ). Detonation nanodiamonds (DND) powder was provided by Plasmachem Compagny (Germany, G02 grade).

\section{Samples preparation:}

Particles were manually milled in a mortar to obtain a fine powder before being modified. Oxidized DND were produced by the annealing of $100 \mathrm{mg}$ of as-received DND placed in an alumina crucible under air for $1 \mathrm{~h} 30$ at $550^{\circ} \mathrm{C}$. They will be designated here as DNDox. Hydrogenated, deuterium-treated or tritium-treated DND were produced either by annealing using appropriate gas or by microwave assisted plasma treatment.

Annealing treatment: $30 \mathrm{mg}$ of DND were placed in a quartz tube $(3.5 \mathrm{~mL})$ with an isolation valve, an in/out gas connection and connected to a cold trap. Vacuum was made and appropriate pressure of gas was loaded. Tube was placed in the oven, and connection was made with trapping set up. Oven was turned for 1 to $4 \mathrm{~h}$ at 450 to $550^{\circ} \mathrm{C}$. Powder was then pumped for 30 min before disconnection and air exposure. For tritium-treated DND, powder was poured in methanol $(4 \mathrm{ml})$ and the solvent was evaporated. The cleaning operation was repeated twice to allow complete removal of labile tritium. Treated DND were stored as a dry powder under nitrogen atmosphere. Annealed particles will be called here A-DND.

Plasma treatment: $20 \mathrm{mg}$ of DND were deposited in a quartz tube and connected to in/out gas and vacuum connection. Appropriate gas was used with a pressure of 12 mbar during the treatment. Sealed tube was inserted into a plasma Downstream source (Sairem SAS, France). Plasma was generated in the quartz tube at a micro-wave power of 100 to $250 \mathrm{~W}(2.45 \mathrm{GHz})$. Multiple loading was done until plasma is stable. During the plasma, the tube was air-cooled. ND were exposed to plasma for $20 \mathrm{~min}$, leading to P-DND.

\section{Suspensions:}

Particles were dispersed in ultrapure water $(18.2 \mathrm{M} \Omega . \mathrm{cm})$ and sonicated (Heilscher UP400s, $300 \mathrm{~W}, 24 \mathrm{kHz}$ ) for $1 \mathrm{~h}$ under a cooling system. To remove highly aggregated particles, the suspensions were centrifuged for $40 \mathrm{~min}(2400 \mathrm{~g}$, $4754 \mathrm{rpm}$ ) followed by supernatant separation. The final concentration was calculated by measuring the mass of particles after drying a calibrated volume of the initial suspension. Note that the amount of particles loss during the centrifugation roughly represent half of the initial mass.

Dynamic light scattering (DLS) and Zeta potential measurements:

Hydrodynamic size and Zeta potential of DND in water suspension were measured on supernatants using Malvern ZetaSeizer Nano ZS. Hydrodynamic size and zeta potential 
analysis were performed with $633 \mathrm{~nm}$ laser at $25^{\circ} \mathrm{C}$ and the scattering angle of $173^{\circ}$. For measurements, the samples were diluted down to $0.1 \mathrm{mg} / \mathrm{mL}$. Zeta potential were measured at the $\mathrm{pH}$ of the native suspension measured at 6.5 , without any adjustment.

Fourier transform infrared (FTIR) spectroscopy:

The FTIR spectra were recorded on a Thermo Nicolet 8700 spectrometer using transmission mode. $\mathrm{KBr}$ pellets $(1 \mathrm{wt} \%$ ) were prepared with DND and dried in-situ under a dry nitrogen flow.

\section{Thermodesorption:}

Desorption is determined by exposing the samples (powder) to air flow ( $500 \mathrm{ml} / \mathrm{min}$ ) until reaching a plateau at determined temperature in the cumulated amount of desorbed tritium. The outlet flow is connected to a tritium analyzer. The remaining tritium concentration in the samples is determined by liquid scintillation counting (LSC).

\section{Liquid scintillation counting:}

Liquid scintillation countings were performed using a Perkin Elmer Tricarb 2910 TR Liquid Scintillation analyzer equipped with automatic external standardization. The samples for liquid scintillation counting were prepared with $10 \mathrm{~mL}$ Ultima GoldTM LLT scintillator in $20 \mathrm{~mL}$ Perkin Elmer super polyethylene vials. For each measurement, 3 countings have been realized and the result given correspond to an average of these 3 values. The global uncertainty, taking into account the one related to the liquid scintillation counter and the uncertainty related to the preparation of the analytic samples, is about $13.5 \%$ for each measurement.

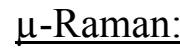

$\mu$ Raman spectra were recorded on a LabRam HR Microspectrometer with an Olympus microscope and an x50 long-range objective. A laser beam with a wavelength of $532 \mathrm{~nm}$ was used as excitation source and the power outputs kept at a value of $\sim 5 \mathrm{~mW}$ to avoid any thermal degradation. $\mu$ Raman spectra were accumulated on a Peltier-cooled CCD camera until a satisfactory signal-to-noise ratio could be obtained. The samples were kept in airtight boxes with a $1 \mathrm{~mm}$ thick glass window. The window revealed the entire surface of the samples, but due to its thickness, conventional higher-order magnification optics with a large optical aperture could not be used. An additional radiological confinement was used for tritiated DND by keeping the samples between a glass slide and a glass lamella glued together using epoxy resin.

\section{NMR:}

NMR spectra have been collected on a Bruker 500WB Avance II NMR spectrometer operating at a magnetic field of $11.72 \mathrm{~T} .{ }^{13} \mathrm{C}$ and ${ }^{2} \mathrm{H}$ MAS NMR spectra have been acquired using a Bruker $\mathrm{HX}$ CPMAS $4 \mathrm{~mm}$ (outer diameter of the $\mathrm{ZrO}_{2}$ rotors) probe at a spinning frequency of 12.5 $\mathrm{kHz}$ and with $\mathrm{cw}{ }^{1} \mathrm{H}$ decoupling at high power $(>80 \mathrm{kHz})$. For ${ }^{13} \mathrm{C}$, we used a rotor-synchronized spin echo pulse sequence with a delay of one rotor period to remove the probe background signal and a recycle delay of $2 \mathrm{~s}$. No change in lineshape is observed for longer delays. For ${ }^{2} \mathrm{H}$, a short single pulse excitation and recycle delay of $2 \mathrm{~s}$ are used. ${ }^{3} \mathrm{H}$ MAS NMR spectra have been acquired using a specific DOTY MAS NMR probe described in ${ }^{44}$ with a single pulse excitation, ${ }^{1} \mathrm{H}$ decoupling and a recycle delay of $2 \mathrm{~s}$. For all $1 \mathrm{D}$ spectra, typically from $1 \mathrm{k}$ to $8 \mathrm{k}$ scans were accumulated. ${ }^{13} \mathrm{C}-{ }^{1} \mathrm{H}$ 1D CPMAS and 2D HETCOR spectra were collected using standard cross polarization with matched RF cw irradiation on both channels (experimentally optimized) and a recycle delay of 1s. All data have been processed and fitted using an in-house 
software (T. Charpentier). ${ }^{1,2,3} \mathrm{H}$ and ${ }^{13} \mathrm{C}$ chemical shifts are referenced to water at $5 \mathrm{ppm}$ and to the carboxyl peak position of alanine (176.5 ppm), respectively.

\section{4) Acknowledgements}

The study was financially supported by French National Research Agency (ANR), project DiamESTar - ANR-14-ENM2-0002-03. Authors would like to thanks M. Mermoux for fruitful discussion on Raman spectroscopy of DND. GP and SF thanks the "programme transverse nanoscience of the CEA" for his support and the funding of the Trinano project. The authors would like to thank Dr. Bernard Rousseau for proof reading of the manuscript and valuable discussions.

\section{5) References}

1. V. N. Mochalin and Y. Gogotsi, Diam. Relat. Mater., 2015, 58, 161-171.

2. M. Ivanov and O. Shenderova, Curr. Opin. Solid State Mater. Sci., 2017, 21, 17-24.

3. N. Gupta, Q. Wang, G. Wen, and D. Su, in Nanodiamonds, ed. J.-C. Arnault, Elsevier, 2017, pp. 439-463.

4. O. A. Shenderova and G. E. McGuire, Biointerphases, 2015, 10, 030802.

5. N. Nunn, M. Torelli, G. McGuire, and O. Shenderova, Curr. Opin. Solid State Mater. Sci., 2017, 21, 1-9.

6. A.-I. Ahmed, S. Mandal, L. Gines, O. A. Williams, and C.-L. Cheng, Carbon N. Y., 2016, 110, 438-442.

7. J. C. Arnault and H. A. Girard, Curr. Opin. Solid State Mater. Sci., 2017, 21, 10-16.

8. T. Kondo, I. Neitzel, V. N. Mochalin, J. Urai, M. Yuasa, and Y. Gogotsi, J. Appl. Phys., 2013, 113, 214307.

9. W. S. Yeap, S. Chen, and K. P. Loh, Langmuir, 2009, 25, 185-191.

10. K. B. Holt, C. Ziegler, D. J. Caruana, J. Zang, E. J. Millan-Barrios, J. Hu, and J. S. Foord, Phys. Chem. Chem. Phys., 2008, 10, 303-310.

11. T. Petit, H. a Girard, A. Trouvé, I. Batonneau-Gener, P. Bergonzo, and J.-C. Arnault, Nanoscale, 2013, 5, 8958-62.

12. J. R. Bertrand, C. Pioche-Durieu, J. Ayala, T. Petit, H. A. Girard, C. P. Malvy, E. Le Cam, F. Treussart, and J. C. Arnault, Biomaterials, 2015, 45, 93-98.

13. J. Hees, A. Kriele, and O. a. Williams, Chem. Phys. Lett., 2011, 509, 12-15.

14. S. Stehlik, T. Glatzel, V. Pichot, R. Pawlak, E. Meyer, D. Spitzer, and B. Rezek, Diam. Relat. Mater., 2016, 63, 97-102.

15. T. Petit, L. Puskar, T. Dolenko, S. Choudhury, E. Ritter, S. Burikov, K. Laptinskiy, Q. Brzustowski, U. Schade, H. Yuzawa, M. Nagasaka, N. Kosugi, M. Kurzyp, A. 
Venerosy, H. Girard, J.-C. Arnault, E. Osawa, N. Nunn, O. Shenderova, and E. F. Aziz, J. Phys. Chem. C, 2017, 121, 5185-5194.

16. R. Grall, H. Girard, L. Saad, T. Petit, C. Gesset, M. Combis-Schlumberger, V. Paget, J. Delic, J.-C. Arnault, and S. Chevillard, Biomaterials, 2015, 61, 290-298.

17. M. Kurzyp, H. A. Girard, Y. Cheref, E. Brun, C. Sicard-Roselli, S. Saada, and J.-C. Arnault, Chem. Commun., 2017, 53, 1237-1240.

18. H. A. Girard, T. Petit, S. Perruchas, T. Gacoin, C. Gesset, J. C. Arnault, and P. Bergonzo, Phys. Chem. Chem. Phys., 2011, 13, 11517.

19. T. Takimoto, T. Chano, S. Shimizu, H. Okabe, M. Ito, M. Morita, T. Kimura, T. Inubushi, and N. Komatsu, Chem. Mater., 2010, 22, 3462-3471.

20. P. Reineck, D. W. M. Lau, E. R. Wilson, K. Fox, M. R. Field, C. Deeleepojananan, V. N. Mochalin, and B. C. Gibson, ACS Nano, 2017, 11, 10924-10934.

21. H. A. Girard, J. C. Arnault, S. Perruchas, S. Saada, T. Gacoin, J.-P. Boilot, and P. Bergonzo, Diam. Relat. Mater., 2010, 19, 1117-1123.

22. V. V Korolkov, I. I. Kulakova, B. N. Tarasevich, and G. V Lisichkin, Diam. Relat. Mater., 2007, 16, 2129-2132.

23. O. A. Williams, J. Hees, C. Dieker, W. Jäger, L. Kirste, and C. E. Nebel, ACS Nano, 2010, 4, 4824-4830.

24. V. Jirásek, Š. Stehlík, P. Štenclová, A. Artemenko, B. Rezek, and A. Kromka, RSC Adv., 2018, 8, 37681-37692.

25. H. A. Girard, A. El-Kharbachi, S. Garcia-Argote, T. Petit, P. Bergonzo, B. Rousseau, and J.-C. Arnault, Chem. Commun., 2014, 50, 2916-2918.

26. G. A. Badun, M. G. Chernysheva, R. Y. Yakovlev, N. B. Leonidov, M. N. Semenenko, and G. V. Lisichkin, Radiochim. Acta, 2014, 102, 941-946.

27. I. Y. Myasnikov, A. V. Gopin, I. V. Mikheev, M. G. Chernysheva, and G. A. Badun, Mendeleev Commun., 2018, 28, 495-496.

28. T. Petit and L. Puskar, Diam. Relat. Mater., 2018, 89, 52-66.

29. C.-L. Cheng, C.-F. Chen, W.-C. Shaio, D.-S. Tsai, and K.-H. Chen, Diam. Relat. Mater., 2005, 14, 1455-1462.

30. M. Mermoux, S. Chang, H. A. Girard, and J.-C. Arnault, Diam. Relat. Mater., 2018, 87, 248-260.

31. M. Mermoux, A. Crisci, T. Petit, H. A. Girard, and J.-C. Arnault, J. Phys. Chem. C, 2014, 118, 23415-23425.

32. Y. Sun and J. Chen, J. Phys. Chem. B, 1997, 5647, 7082-7086.

33. L. Schmidlin, V. Pichot, M. Comet, S. Josset, P. Rabu, and D. Spitzer, Diam. Relat. Mater., 2012, 22, 113-117.

34. T. Petit, J.-C. Arnault, H. A. Girard, M. Sennour, T.-Y. Kang, C.-L. Cheng, and P. Bergonzo, Nanoscale, 2012, 4, 6792.

35. O. A. Shenderova, I. Petrov, J. Walsh, V. Grichko, V. Grishko, T. Tyler, and G. 
Cunningham, Diam. Relat. Mater., 2006, 15, 1799-1803.

36. D. Ballutaud, F. Jomard, J. Le Duigou, B. Theys, J. Chevallier, A. Deneuville, and F. Pruvost, Diam. Relat. Mater., 2000, 9, 1171-1174.

37. L. H. Reddy, H. Khoury, A. Paci, A. Deroussent, H. Ferreira, C. Dubernet, X. Declèves, M. Besnard, H. Chacun, S. Lepêtre-Mouelhi, D. Desmaële, B. Rousseau, C. Laugier, J.-C. Cintrat, G. Vassal, and P. Couvreur, Drug Metab. Dispos. , 2008, 36, $1570-1577$.

38. X. Fang, J. Mao, E. M. Levin, and K. Schmidt-Rohr, J. Am. Chem. Soc., 2009, 131, $1426-35$.

39. A. M. Panich, Diam. Relat. Mater., 2017, 79, 21-31.

40. M. Dubois, K. Guérin, N. Batisse, E. Petit, A. Hamwi, N. Komatsu, H. Kharbache, P. Pirotte, and F. Masin, Solid State Nucl. Magn. Reson., 2011, 40, 144-154.

41. O. Shenderova, A. M. Panich, S. Moseenkov, S. C. Hens, V. Kuznetsov, and H.-M. Vieth, J. Phys. Chem. C, 2011, 115, 19005-19011.

42. A. M. Panich, Crit. Rev. Solid State Mater. Sci., 2012, 37, 276-303.

43. O. Shenderova, A. M. Panich, S. Moseenkov, S. C. Hens, V. Kuznetsov, and H.-M. Vieth, J. Phys. Chem. C, 2011, 115, 19005-19011.

44. A. K. L. Yuen, O. Lafon, T. Charpentier, M. Roy, F. Brunet, P. Berthault, D. Sakellariou, B. Robert, S. Rimsky, F. Pillon, J.-C. Cintrat, and B. Rousseau, J. Am. Chem. Soc., 2010, 132, 1734-1735. 